\title{
ESCREVER E INSCREVER A MATERNIDADE POR MEIO DOS BLOGS
}

\author{
Maria Consuêlo Passos \\ Universidade Católica de Pernambuco \\ Isabela Lemos Arteiro \\ Universidade Federal da Paraíba
}

\begin{abstract}
Resumo
Tornar-se mãe exige a elaboração de uma posição subjetiva diante do filho. As formas de enfrentamento da maternidade são singulares e revelam transformações diferentes em cada época. Nessa perspectiva, o objetivo desse trabalho é discutir algumas expressões atuais da maternidade que são reveladas em blogs. O estudo enfatiza o recurso da escrita de mulheres nesses espaços, onde elas discutem suas dificuldades com os cuidados com os bebês, a sobrecarga que esse novo lugar de mãe impõe quando vem associado a papeis profissionais, e a solidão no enfrentamento das novas tarefas. O material examinado foi retirado de alguns blogs onde as trocas revelavam novos sentidos sobre o processo de construção da maternidade. A análise foi feita com /o aporte da psicanálise winnicottiana. Tal procedimento revelou que o endereçamento à diferentes parceiras, facilitava o processo de elaboração de muitas dificuldades enfrentadas pelas mulheres com seus bebês e famílias.
\end{abstract}

Palavras-chave: maternidade; mulheres; bebês; blogs; psicanálise.

\section{WRITE AND INSCRIBE MATERNITY THROUGH BLOGS}

\begin{abstract}
To become a mother requires the elaboration of a subjective position in front of the child. The forms of coping with motherhood are singular and reveal different transformations in each era. From this perspective, the purpose of this paper is to discuss some current expressions of motherhood that are revealed in blogs. The study emphasizes the writing resource of women in these spaces, where they discuss their difficulties with the cares of babies, the overload that this new place of mother imposes when associated with professional roles, and the loneliness in facing new tasks. The material examined was taken from some blogs where exchanges revealed new meanings about the process of building motherhood. The analysis was made with the support of Winnicott's psychoanalysis. This procedure revealed that addressing different partners facilitated the process of elaborating the many difficulties faced by women with their babies and families.
\end{abstract}

Keywords: maternity; women; babies; blogs; psychoanalysis.

\section{ESCRIBIR E INSCRIBIR LA MATERNIDAD POR MEDIO DE LOS BLOGS}

\begin{abstract}
Resumen
Convertirse en madre requiere la elaboración de una posición subjetiva ante el niño. Las formas de hacer frente a la maternidad son singulares y revelan diferentes transformaciones en cada época. Desde esta perspectiva, el propósito de este artículo es discutir algunas expresiones actuales de la maternidad que se revelan en blogs. El estudio enfatiza la característica de escribir de mujeres en estos espacios, donde discuten sus dificultades para cuidar a sus bebés, la sobrecarga que impone este nuevo lugar de madre cuando asociado con roles profesionales, y la soledad frente a nuevas tareas. El material examinado fue tomado de algunos blogs, donde los intercambios revelaron nuevos significados sobre el proceso de construcción de la maternidad. El análisis se realizó con apoyo del psicoanálisis de Winnicott. Este procedimiento reveló que dirigirse a diferentes parejas facilitó el proceso de elaboración de muchas dificultades que enfrentan las mujeres con sus bebés y familias.
\end{abstract}

Palabras clave: maternidad; mujeres; bebes; blogs; psicoanálisis. 


\section{INTRODUÇÃO}

Quando lançamos um olhar histórico sobre os sentidos da maternidade, logo nos deparamos com o fato de que estes se formam, em grande medida, a partir dos princípios socioculturais de uma dada época, que interferem na constituição dos laços de afeto criados no interior da família. Desse modo, em cada cultura e em cada momento histórico existe um modelo a partir do qual as mulheres se situam em relação à maternidade e através do qual serão regidas suas condutas.

À medida que os sentidos da maternidade foram se modificando ao longo do tempo, o lugar da infância também sofreu profundas transformações: tratada como um pequeno adulto, a criança passa a ser libidinizada a partir da emergência do "sentimento de infância" (Ariès, 1978). Os bebês têm recebido sentidos diversos ao longo da história da humanidade - de estorvo para os pais tornaram-se "a majestade, o bebê" em um intervalo temporal de pouco mais de um século (Postman, 1999). Esses dois fatores se retroalimentam, ou seja, a compreensão a respeito da criança produz novos sentidos sobre a maternidade e vice-versa.

Tais reflexões adquirem peso significativo a partir das contribuições psicanalíticas. Embora grande parte das construções teóricas da Psicanálise sejam datadas, elas nos permitem compreender alguns fenômenos contemporâneos e, além disso, realizar o exercício crítico de atualizar várias de suas noções auxiliares. É com essa perspectiva, que chamaremos Winnicott como intérprete de certas posições assumidas pela mulher em relação à criação de sua função como mãe.

A Psicanálise teve um papel fundamental ao longo do século $X X$ na ratificação do discurso que atrela o papel materno às exigências sociais. No texto 'A contribuição da mãe para a sociedade', Winnicott (1957/1989) é enfático ao descrever a importância da maternagem nos seguintes termos:

Estou preocupado com a relação que a mãe tem com o bebê pouco antes do e nas primeiras semanas e meses após o nascimento. Estou tentando chamar a atenção para a imensa contribuição ao indivíduo e à sociedade que a boa mãe comum faz desde o começo, com o seu marido dando suporte, e que ela faz simplesmente por ser devotada ao filho. (Winnicott, 1957/1989, p. 98).

Winnicott propõe que a chegada do bebê promove uma transformação na mulher, levando-a a uma dedicação quase absoluta ao filho, tornando o pai, nesse momento, a retaguarda que assume o lugar de guardião da mãe. O autor destaca a importância da "mãe devotada comum", aquela que por estar em profunda conexão com seu bebê é capaz de perceber o que ele necessita e atendê-lo de modo suficientemente bom. Considera que naturalmente as mulheres teriam disposição a desenvolver essa prontidão ao bebê, não necessitando que isso fosse transmitido por outrem. Para ele: "Não há regras 
nem livros que possam suprir essa intuição que a mãe tem das necessidades do bebê, a qual lhe permite realizar, algumas vezes, uma adaptação quase exata a essas necessidades" (Winnicott, 1949/2014, p. 49).

Por naturalizar as condições da mulher e da família no que concerne ao exercício da maternidade, as posições do autor vêm sendo criticadas. Sem dúvida, é necessário ressignificar a ênfase dada por Winnicott à presença exclusiva da mãe nesse território, outrora, "quase sagrado".

Um ponto central de crítica é a concepção de mãe que é forjada a partir de um enquadre histórico específico, na qual o desejo por filhos e a dedicação aos mesmos era um imperativo para as mulheres. Reduzida em grande medida tal imposição, hoje as mulheres buscam outras formas de expressão de si e procuram debater suas contradições e conflitos, inerentes à construção de uma postura subjetiva frente aos filhos e à família (Lipovetsky, 2000).

$\mathrm{Na}$ cultura ocidental, a demanda pela maternidade é muito presente e se revela, sobretudo, após o casamento. Reivindicar o direito de não ter filhos ou mesmo questionar as dificuldades enfrentadas no dia a dia da maternidade, entretanto, tem se tornado cada vez mais frequente. Hoje, muitas mulheres estão tentando dar conta das diferentes demandas tanto da vida privada como da vida pública, o que tem evidenciado diferentes formas de enfretamento das múltiplas funções. Em muitas situações, os casais adiam o projeto de filhos, privilegiando a consolidação do projeto profissional antes da chegada destes.

A saída da posição fixa de entrega absoluta à maternidade enseja um tempo novo e exige performances diferentes das mães, dos seus parceiros, das famílias e das instituições. Nesse sentido, para além do reconhecimento social de seu lugar como mãe, é necessário um trabalho de elaboração dessa nova mãe, no sentido de constituir psiquicamente esse lugar.

Iaconelli (2015) aponta que reconhecimento e nomeação são dois aspectos fundamentais para o exercício da função materna, sendo necessário serem subdivididos em reconhecimento do bebê como um filho pertencente à linhagem parental e no reconhecimento da mulher enquanto mãe. Quando alguém reconhece um bebê como seu, atribui a ele o valor de pertença, diretamente associado ao investimento narcísico da mãe. Desse modo:

Uma mãe, nos primeiros contatos com o bebê, diante desse estranho deverá atribuir-lhe algo seu, digamos, deverá ser capaz de ver-se no bebê, para que este possa ser reconhecido na filiação como sendo o bebê dela e do pai por ela escolhido. (Iaconelli, 2015, p. 161).

Neste sentido, o processo de filiação depende de um trabalho psíquico dos pais, que Ihes permita inserir simbolicamente o filho na cadeia familiar de origem, que, aliás, foi iniciada em outras gerações. Esse trabalho implica também, necessariamente, a presença de um outro social. Ainda de acordo com Iaconelli (2015), para que a mãe possa vir a nomear o seu bebê, ela não pode 
prescindir do reconhecimento e da sustentação que o outro e a cultura podem Ihe oferecer, nomeando-a como mãe.

Esse trabalho parte, portanto, da hipótese de que a busca pelo reconhecimento, não só do lugar materno, mas também dos dilemas que essa experiência suscita, são fundamentais para que as mulheres possam investir em sua nova posição subjetiva junto à criança. Embora hoje as mulheres compartilhem muito mais com seus companheiros os cuidados com os filhos, os compromissos profissionais, bem como o grande investimento nas trocas físicas e emocionais com um novo bebê, demandam um trabalho psíquico que muitas vezes elas encontram dificuldades em realizar. Esse trabalho diz respeito a um processo de adaptação à nova criança, que lhe mobiliza tanto física quanto subjetivamente e implica em descobertas, em uma situação na qual prepondera simultaneamente um não saber sobre o bebê e a construção de uma relação de afeto. Tais circunstâncias, muitas vezes, tornam as mulheres vulneráveis, apresentando dificuldades na construção de sua nova posição subjetiva de mãe.

É nesse contexto que Braga (2008) aponta para uma contribuição importante dos espaços cibernéticos que, quando utilizados como lugar de troca de experiências, podem desempenhar uma função continente na elaboração das experiências advindas do processo de tornar-se mãe. A interlocução com outras mulheres que vivem dificuldades semelhantes na descoberta e construção de um lugar materno, parece favorecer uma cumplicidade e o suporte necessários para que elas possam expressar, com mais espontaneidade, seus conflitos e vulnerabilidades.

Partindo dessas reflexões, foi possível elaborarmos o objetivo desse trabalho que é discutir expressões da maternidade compartilhadas por mulheres em blogs onde elas revelam seus conflitos, dificuldades e saídas encontradas em diferentes formas de ser mãe. Parte-se do princípio de que o uso dos blogs é um recurso que pode facilitar a construção da maternidade.

Os fundamentos teóricos e metodológicos desse trabalho têm sua origem em uma tese de doutorado intitulada: "A mulher e a Maternidade - Um exercício de reinvenção".

\section{MÉTODO}

O ponto de partida para a operacionalização do trabalho empírico foi a busca feita no Google, pelos blogs de maternidade e em seguida, uma seleção daqueles que seriam utilizados, tomando como critérios os títulos, o layout e a organização de cada um, pois estes indicavam, com mais facilidade, aquilo que buscávamos, que era a escrita de experiências das mulheres, em seus processos de tornar-se mãe. Foram selecionados sete blogs que tinham a participação de mulheres de classe média, que descobriram esse espaço cibernético como uma 
possibilidade de diálogo, com parceiras que viviam experiências muito semelhantes no processo de tornar-se mãe.

Após esta seleção, foram feitas as leituras da seção onde as autoras escrevem um texto sobre suas histórias de vida e a motivação para a criação desses espaços. Na sequência, foi possível fazer uma leitura das escritas sobre as experiências cotidianas onde as mulheres expressavam livremente seus conflitos e sentimentos vividos com seus bebês, mas também procuravam expor suas tentativas de reinventar a relação com a maternidade. Os fragmentos das escritas foram nomeados de acordo com as mensagens mais expressivas que eles transmitiam.

As discussões foram feitas com base no referencial psicanalítico voltado para questões relativas à maternidade, e os desafios vividos pelas mulheres na relação com seus bebês. Constatou-se grande escassez de material com abordagens específicas sobre as escritas das mulheres nesse espaço, o que nos levou à busca de material bibliográfico sobre assuntos e temáticas paralelas que margeavam a questão proposta.

No contexto geral, a Psicanálise winnicottiana se constituiu como referência central no debate, não só das questões relativas à maternidade, mas também dos resultados obtidos com a leitura da escrita das mulheres/mães. Esse referencial propõe uma atenção livre do conteúdo, possibilitando assim a apreensão do todo, sem perda dos detalhes, principalmente daqueles que indicam a presença de metáforas e de conteúdos latentes.

\section{RESULTADOS E DISCUSSÕES: ESCRITA DA MATERNIDADE}

A utilização dos blogs pelas mulheres-mães indica o quanto estes se tornaram, nos últimos anos, recursos que facilitam a comunicação entre pessoas que, muitas vezes, carecem de espaços de intimidade para a troca de experiências.

Braga (2008), em seu livro 'Persona materno-eletrônicas - feminilidade e interação no Blog Mothern', reflete sobre o uso contemporâneo da internet e de algumas apropriações sociais dos ambientes digitais e revela como essa combinação articula lógicas de identidade, de relacionamento e de poder. Para essa autora, o poder médico que preponderou no século $X X$, hoje convive com lugares de interação criados pelas novas tecnologias, onde as mulheres colocam em xeque a postura do especialista, em prol de um saber oriundo de suas experiências singulares. Ela refere que:

Enquanto a conversação entre mulheres sobre filhos, vida conjugal e doméstica tem sido desvalorizada socialmente, enquadrada como conversa fútil e enfadonha, no ambiente social dos blogs essa mesma temática se estabelece sem a conotação pejorativa e, ao contrário, é entendida como prática de mulheres modernas pelo engajamento tecnológico. (Braga, 2008. p. 17) 
A internet parece se inscrever como um local de fronteira entre o público e o privado, onde questões de foro íntimo, públicas e profissionais se intercalam. Ao mesmo tempo em que uma profissional está redigindo um ofício no trabalho, por exemplo, em outra janela ela pode estar participando de chats de discussão sobre maternidade, atualizando um post em seu blog ou comentando um post de outra participante. De acordo com Braga (2008, p.61): "O ambiente midiáticotecnológico desse blog - a exemplo de muitos outros na rede -, oferece a possibilidade de combinar essas duas perspectivas femininas, propondo uma solução para esse aparente paradoxo: ser materna e moderna ao mesmo tempo".

Embora não tenha sido possível encontrar um número exato de blogs em funcionamento, é possível afirmar que há hoje um aumento cada vez maior de mulheres que se utilizam de recursos tecnológicos e midiáticos para divulgar as experiências relativas à maternidade. Os blogs visitados nessa pesquisa foram criados e utilizados por mulheres em sua maioria de classe média, que exercem suas carreiras profissionais, ao mesmo tempo que assumem suas funções maternas. Para essas mulheres, a escrita íntima parece explicitar a demanda por um espaço de elaboração de experiências relativas à maternidade, a fim de que a "nova" e, por vezes, "estranha" condição de mãe possa tornar-se familiar.

Em face do avanço tecnológico, assistimos à transição da escrita em pequenos cadernos e diários, para a publicação de conteúdos íntimos nos dispositivos que compõem o ciberespaço e disponíveis à visualização de qualquer visitante. Na atualidade, é possível depararmo-nos com escritas da intimidade através de recursos virtuais. Nos blogs, os autores escrevem em primeira pessoa, descrevendo sentimentos íntimos, conflitos, e demais experiências subjetivas, buscando sempre um endereçamento. Vejamos o que diz uma das participantes:

Querido diário virtual, hoje eu perdi a paciência, o controle, a razão... e extrapolei na emoção. Não lembro quantas vezes respirei fundo e contei até 60 , mas lembro que em uma das vezes contei até quase mil... e a raiva não passou, a razão não voltou. Eu poderia te dizer que está tudo bem, diário. Mas não tá, não. Vou dormir com o coração em pedaços e com uma sensação profunda de impotência, incapacidade. Um misto intenso de "será que fiz as escolhas erradas?" (Blog 4, 27/01/2017).

Em meio ao ataque de nervos, quando a razão, a paciência e o controle dão lugar ao desespero, à desorganização e às dúvidas, a escrita parece fazer a função de balizamento para a organização subjetiva da mãe em questão. Ainda que a sensação volte muitas vezes, temos a impressão de que a escrita engendra a consciência de si, de seus limites e contornos, favorecendo uma organização psíquica a cada vez que o turbilhão afetivo reaparece. A escrita sobre a impotência vivida com a maternidade parece funcionar como um modo de criação e invenção de si enquanto mãe. A cada palavra, a cada 
reconhecimento, essas mulheres parecem apropriar-se de seu interior quando diante do cenário de incertezas que a maternidade pode representar.

Entendemos, desta maneira, que a busca por espaços como os blogs pode funcionar como tentativa de criar formas de apoio à vida familiar, cumprindo, assim, duas finalidades. Por um lado, o compartilhamento dos desafios relativos aos cuidados com o bebê e, por outro, a busca de um reconhecimento social do papel materno. Em outros momentos, o reconhecimento e compartilhamento de experiências eram feitos entre as mulheres da própria família, que funcionava como apoio na recepção e cuidados do bebê. Hoje, muitas mães demonstram enfrentar certas limitações no que tange ao apoio familiar, tendo em vista que a disponibilidade das genitoras de suas famílias é bem mais limitada. Surge daí a busca por outras formas de apoio.

Nos blogs elas encontram referências mais aproximadas de suas realidades, podendo assim expressar seus dilemas e ansiedades emergentes. Através dos depoimentos, que se apresentam como uma tentativa de "tudo dizer" sobre a maternidade (mesmo diante do confronto com a insuficiência das palavras), muitas mães consideram possível acessar "verdades" até então escondidas.

No texto disponibilizado na internet, a escrita é dirigida a um outro, havendo assim uma certa torção no fechamento em si mesmo, próprio ao monólogo narcísico da escrita íntima. Para Lobo (2007), o que está em jogo aí é muito mais uma demanda de compartilhamento das emoções e das experiências pessoais. Segundo a autora, há uma interferência no processo de subjetivação, quando o sujeito que escreve se dá conta de que há, em qualquer lugar do mundo, alguém que possa compartilhar das suas experiências, seus dilemas, etc. Muitas identificações surgem daí e, às vezes, até vínculos são criados.

De um modo geral, nas escritas das mulheres, deparamo-nos com múltiplas facetas dos seus cotidianos: de um lado, alegria e realização; de outro, incerteza, medo, angústia - afetos que comumente são calados, pois expressam o avesso do ideal construído socialmente sobre o que seja ser mãe.

A seguir traremos três aspectos que se destacaram nas interlocuções das mulheres nos blogs visitados. O primeiro trata da desidealização vivida pelas mulheres após o nascimento dos filhos que, embora gere muitas ambivalências, é fundamental para a construção dos laços com o bebê.

O segundo diz respeito às dificuldades vividas pelas mães no que concerne ao tempo que, nesse momento de exacerbação das responsabilidades, acaba por gerar muita ansiedade. Isso exige um certo redimensionamento da forma como a mãe se movimenta subjetivamente no seu ambiente cotidiano.

O último aspecto refere-se ao desafio enfrentado pela mulher que, ao assumir sua função de maternar, precisa dividi-la com seus outros compromissos relacionais e profissionais. Trata-se de realizar um grande trabalho psíquico que 
é integrar as várias facetas que Ihes são impostas no dia a dia, aprendendo a atribuir prioridades, nem sempre favoráveis ao exercício do cuidado materno.

"Eu pensava não ser bem assim..."

No mundo há lugar para todos os tipos de mãe; algumas farão bem um tipo de coisa, outras terão sucesso em outro tipo de coisa. (Winnicott, 2012/1988, p. 16).

Essa posição do autor evidencia a impossibilidade de pensarmos de forma hegemônica o conceito sobre maternidade. Além disso, chama a atenção para o fato de que o amor materno como um afeto inabalável e instintivo não tem sido suficientemente desconstruído nos últimos tempos. A despeito dos modos de se operar com a maternidade e o desejo por filhos não se apresentar como outrora, o ideário da "mãe perfeita" ainda se sustenta no imaginário social.

Isto significa dizer que a sociedade é, em certa medida, intolerante às ambivalências oriundas dessa experiência, o que talvez explique ou pelo menos justifique o silenciamento de muitos afetos referentes à maternidade. Contudo, contrariando essa afirmação, vemos crescer uma série de discursos que se posicionam de maneira diametralmente oposta, com vistas a impugnar a representação romantizada do papel materno, conforme identificado nos depoimentos a seguir:

Às vezes, a gravidez não chega com trilha sonora e sim com um rosário de preocupações com o futuro da sua carreira e/ou do seu relacionamento, com as formas do seu corpo, o preço da escola particular, ou poucos meses de licença maternidade e o mundo violento que essa criança vai herdar. E não há nada de errado em se sentir assim, já vou deixar claro, a gente experimenta diversos sentimentos durante essa fase e a felicidade pode ser apenas um deles. (Lisauskas, 2017a, p.20).

É comum encontrarmos nos blogs depoimentos que convocam as mulheres a pensarem na maternidade como uma experiência também dolorosa. Muitas vezes há resistências das mulheres a pensarem assim, já que foram socializadas para criarem uma imagem unilateral que enaltece a positividade da experiência materna.

O modo como algumas parturientes são tratadas e as palavras ditas no pré-natal, parto e puerpério provocam uma marca significativa no encontro mãebebê. As expectativas, sonhos, medos, inseguranças se entremeiam com os ditames do especialista, promovendo uma "confusão de vozes". Há um risco de que os discursos do biopoder, as intervenções médicas abusivas e as negligências incidam sobre o corpo da mãe e do bebê, dificultando o encontro da dupla. Essa foi uma preocupação também apontada por Winnicott (1957/1989) que sempre afirmava uma força positiva da mulher que lhe protegia de certas adversidades: "O amor da mãe é algo semelhante a uma força primitiva. Nele se conjugam o instinto de posse, o apetite e até certo elemento de contrariedade, em momentos de exasperado humor; e há nele generosidade, energia e 
humildade também". Essa ambivalência aparece de forma clara em muitos depoimentos das mães:

$\mathrm{Na}$ minha trajetória como mãe tive momentos de pura delicadeza. Momentos em que eu olhava para as minhas filhas com vontade de chorar, de tanta felicidade. Momentos em que meu coração parecia explodir de amor. E também momentos de puro terror, daqueles de sentar no banheiro sozinha querendo fugir. Ninguém consegue ser feliz o tempo todo no trabalho, na vida a dois como mãe, ou até consigo mesmo (Blog 5, 19/02/2016).

Se por um lado encontramos mulheres que concebem a maternidade como uma expansão e ressignificação dos sentidos da existência, por outro verificamos que muitas delas a consideram uma experiência de castração e de impedimentos para a realização de futuros projetos. Essas ambiguidades parecem estar relacionadas à criação imaginária de expectativas e desejos. A esse respeito, afirma uma mãe:

O nosso menino chegou... Fiquei realmente emocionada ao ouvir o chorinho dele... Porém, quando colocaram ele na minha frente, não senti aquele amor arrebatador que todas as minhas amigas sempre diziam que acontecia... Me senti realmente muito mal... (Blog 1, 01/08/2015).

É possível verificar nesse depoimento que o nascimento inaugura uma ruptura com a relação imaginária, abrindo espaço para que a mãe se encontre com o bebê real, mas nem sempre esse processo acontece imediatamente após o parto. Algumas mães levam algum tempo buscando características de cada um dos pais para facilitar a adoção do próprio filho. Conforme afirma Benhaïm (2007, p. 51):

Se a mãe aceita, tão logo seu filho venha ao mundo, fazer o luto daquele que ela trazia em si, não somente em seu corpo, mas também em seus fantasmas, ela poderá amá-lo por ser este outro, e /1957ao mesmo tempo, odiá-lo por já ser um outro.

Tudo isso nos revela que, apesar do bebê ter sido carregado pela mãe por nove meses em seu corpo, ele representa um desconhecido que precisará ser incorporado em sua vida mental, social e afetiva. O vínculo entre os "estranhos", mãe e filho, nem sempre se constitui imediatamente após o nascimento. A passagem do bebê imaginado para o bebê real que comparece logo após a cena do parto é geradora de um "intervalo", no qual a mulher se depara com a demanda de criar laço com o filho, ao mesmo tempo que enfrenta um estranhamento em relação a esse bebê que the exige dedicação e mesmo devoção (Winnicott, 1989/1957).

Sobre o tempo: reduzido, repartido, roubado...

$\mathrm{Na}$ maior parte dos blogs há um consenso quanto à presença de depoimentos que mencionam a relação com o tempo, referindo ser este um dos maiores desafios a ser enfrentado pelas mães. Essa temática não é novidade e 
nem tampouco apenas efeito de uma geração para a qual o imediatismo e a rapidez tornaram-se características evidentes.

A chegada de um bebê gera uma avalanche de demandas direcionadas à figura materna que, por sua vez, emitirá resposta a partir de suas condições físicas, psíquicas, etc., que, quase nunca correspondem ao ideal de presença criado no imaginário das mulheres. Vejamos a metáfora:

Os primeiros tempos com um bebê são como um CD de heavy metal que vai tocar em looping. Você não consegue reconhecer as notas, a guitarra está alta e distorcida, a bateria e o baixo são densos e o vocalista está gritando na sua orelha. E isso é normal, tá? Quando a gente sabe que o show que está programado é esse, não o banquinho e o violão do João Gilberto, fica mais fácil aceitar e saber que não, o problema não é com a gente. Não, o problema não é com o seu bebê. (Lisauskas, 2017b, p.58)

Para essa mãe, a chegada do filho gera uma espécie de estranhamento no qual é preciso se recompor para pouco a pouco entender a nova condição que, por mais que tenha sido imaginada, não combina com a intimidade necessária à recepção da criança. Prepondera sempre, nessa situação, um desconhecimento da própria experiência, um não saber sobre o que fazer para se aproximar da criança que depende de forma absoluta dos seus cuidados. Assim, a mãe precisa, nesse momento, se haver não só com as transformações que estão sendo processadas física e psiquicamente consigo, mas também, por meio da identificação, reconhecer as necessidades da criança e responder a elas. É por essa via da identificação que ambas conseguem exercitar o trabalho necessário de investimento de afetos, a partir do qual o laço parental primário será criado. Evidentemente, esse processo implica em insegurança, ansiedade e demanda um tempo de amadurecimento.

Passei exatos onze meses buscando na internet dicas de como fazer minha filha dormir. Tentei a rotina do sono, banho antes de dormir, massagem, tomei litros de chá de camomila, ouvi todos os conselhos: mãe, sogra, tia, moça do blog, mulheres do grupo, enfermeira e pediatra. Acredite, tudo que lia e não achava absurdo, ganhava lugar na minha lista de tentar fazê-la dormir. (Blog 7, 18/03/2015).

Pois bem, nada era suficiente para conciliar o sono da bebê, até o dia que a mãe resolveu assumir suas impossibilidades de lidar com o tempo, procurando normatizar os momentos de conexão com a filha. Admitir que ela não dormia e que os "conselhos" dos outros não resolviam, foi libertador. Além disso, as trocas e os acolhimentos obtidos nos blogs, foram a sustentação que necessitava para enfrentar uma experiência impossível de ser evitada com lições e na correria das inúmeras tarefas.

Provavelmente, o esgotamento materno não se devia apenas às noites mal dormidas, mas também ao duelo interior vivenciado entre suas próprias demandas e as necessidades da filha, entre o seu tempo e o timing de sua pequena, desafiando-se para fazer esses dois polos se coadunarem. Parecia 
haver um grande esforço no sentido de uma compreensão da alteridade e temporalidade de sua filha com suas especificidades e particularidades, compreendendo que esta é uma condição que não poderia lutar contra, e o encontro com os elementos de sua maternalidade, acessados quando a mãe deixou de buscar referências para o seu "fazer materno" fora de si. A partir de então, a mãe passa a experimentar um sentimento de confiança em relação ao seu novo papel, conforme sinalizado nas palavras a seguir:

Um dos dias mais felizes e libertadores da minha vida foi quando me perguntaram se Helena dormia a noite inteira e respondi que não. Helena não dorme uma noite inteira e é terrível isso às vezes, mas estamos bem, é uma fase e a acolhemos como é. (Blog 7, $18 / 03 / 2015)$.

Nesse caso, a experiência entre mãe e filha tornou-se mais espontânea a partir do momento em que o acolhimento à temporalidade, ritmicidade e alteridade de sua bebê foi possível. Ademais, a escrita do depoimento parece ter tido uma função organizadora para esta mãe, possibilitando o reconhecimento de sua transformação e das possibilidades para cuidar da filha.

Em outro depoimento, encontramos uma visão do tempo marcada pela singularidade dos afetos, diz uma mãe:

Nas minhas reflexões ao escrever este post, defini o tempo sentimental como um processo mensurado não pelos minutos e segundos do velho mundo cartesiano e, sim, um processo mensurado pela alma, pelas emoções, sentimentos, muita paciência e muito "tempo" para que haja muitas pausas em nosso corpo biológico. 0 tempo cronológico nos diz que a vida não para em nenhum segundo, mas o tempo sentimental é capaz de nos pausar, de nos mostrar que temos todo o tempo do mundo. Um tempo mensurado por nós mesmos, pelos nossos anseios e, principalmente, pela nossa alma recheada de lembranças e cenas vividas que podem ser experimentadas em qualquer circunstância. (Blog 2, 28/04/2013).

Para essa mãe, assim como para todas as outras, "o tempo não para", e dessa forma, não é a cronologia das horas e dos minutos que rege suas ações, mas o tempo sentimental, aquele capaz de fazê-la parar a fim de viver, no presente, a criação de si pela via da criação do laço materno.

Eu precisava integrar essas mulheres dentro de uma só...

Lá vai ela, a apenas mãe. Faz almoço, dá banho, troca a roupa, escova os dentes, penteia os cabelos... nessa vida de apenas mãe ela virou enfermeira, cabeleireira, professora, motorista, cozinheira e terapeuta em tempo integral. Ela virou equilibrista, palhaço e, por último, mas não menos importante, "enxugadora de lágrimas". (Blog $4,16 / 02 / 2017)$.

Integrar suas diferentes facetas na vida cotidiana tem exigido um grande esforço das mulheres que enfrentam suas atribuições públicas e privadas com o sentimento de incompletude e falta. Tal experiência é quase sempre exacerbada pelos imperativos de normatividades sociais que exigem delas agilidade e 
exercícios de alta performance. A parceria nesse desempenho existe, mas, nem sempre se faz de forma espontânea. Algumas vezes se coloca como participações excepcionais e de boa vontade dos pais, embora a inserção destes na vida privada e na divisão das tarefas parentais tem tido um avanço significativo na sociedade brasileira. Diz uma mãe:

Quando girei a maçaneta ouvi passinhos rápidos em direção à porta. Ela estava acordada. Aquele abraço - com bracinhos pequenos e mãos delicadas - me preencheu imediatamente. E fez com que o choro que eu tinha sufocado na garganta explodisse, incontrolável. Ela tinha apenas 1 ano e alguns meses. [...] E foi quando percebi nitidamente o que era a angústia da separação que não sentira desde então, por ter tido o privilégio único de estar com ela todo aquele tempo. Entrei no banho para tentar me desvincular daquela mulher que correra por aeroportos, táxis, reuniões e notei seus olhinhos suplicando minha presença. Deixei que ela entrasse no banho comigo. E de repente me dei conta de que aquele era o único compromisso inadiável que eu tinha na vida. (Blog 5, 09/07/2015).

Esse dilema é vivido cotidianamente por milhares de mulheres que, embora venham adquirindo melhores condições no enfrentamento de suas jornadas de trabalho, como por exemplo, locais onde deixar as crianças, espaço de trabalho dentro da própria casa, rede de apoio que sustenta as crianças nas suas ausências, nada disso elimina o sentimento de falta em relação aos cuidados com os filhos. Nesse sentido, Lipovetsky (2000, p. 250) afirma: "A dinâmica igualitária conseguiu desqualificar a associação do homem com a autoridade, mas não chegou a arruinar a associação das mulheres com as responsabilidades domésticas".

Mesmo sendo comum hoje as mães assumirem suas vidas profissionais, não é sem consequências que isso acontece, sobretudo quando se dão conta de que ainda estão envoltas em uma divisão de poder social que mantém a primazia das mulheres diante dos cuidados com os filhos. Em outros termos, o cuidado que o homem dedica à família, ainda é mantido em segundo plano em relação aos seus investimentos profissionais no mundo público. A esse respeito Belo (2015) comenta que, quando um homem deseja cuidar de um bebê, na posição de pai, tem-se uma relação libidinal como qualquer outra, isto é, sujeita a todas as vicissitudes pulsionais. Esta ideia é concebida a partir de uma lógica muito simples: tendo o pai vivido experiências arcaicas de cuidado quando era um bebê, terá elementos dessa situação originária para serem atualizados nos cuidados com o filho, tal qual a mãe. Desse modo, não é o fato de gerar uma criança que habilita uma mulher a cuidar de seu bebê, e sim a experiência de ter sido um bebê um dia.

Partindo dessa concepção, Ferreira e Aiello-Vaisberg (2006) propõem a denominação "cuidador devotado comum". Com tal proposição não descartam o fundamento teórico que sugere um cuidado espontâneo, autêntico, integrado e operado por um "verdadeiro self", porém não estão de acordo que ele deva se 
restringir exclusivamente à mãe, uma vez que existem outras situações humanas caracterizadas pelo cuidado fundamental. Segundo as autoras:

Aqui estamos contemplando a devoção a acontecer de forma espontânea, autêntica, como o é na maioria do tempo visto com a mãe "preocupada" comum, mas que pode ser reportado ao cuidado realizável, também, por outros que não a mãe, como os pais, avós, tios, professores, por alguém interessado em criar. Essa forma de pensar faz muito sentido, quando nos remetemos às famílias adotivas. (Ferreira \& Aiello-Vaisberg, 2006, p. 141).

No Brasil, o paradigma da divisão de tarefas por gênero, seja no que concerne aos papéis familiares ou às tarefas domésticas, vem sendo modificado paulatinamente. Porém, trata-se de um movimento incipiente em algumas localidades do território nacional. Lisauskas (2017b) sugere:

[...] preciso lembrar que está nas mãos da nossa geração mudar a maternidade e a paternidade do futuro. [...]. Nenhuma mãe nasce mãe, mas ela é educada a vida inteira para ser mãe. Nenhum pai nasce pai, mas os meninos são desestimulados a vida inteira a se transformarem pais. Se não podem brincar de boneca, nem de casinha, nunca puderam lavar a própria roupa ou tirar um prato da mesa, como esperar que eles entendam no futuro o que é uma vida a dois? (Lisauskas, 2017b, p.89).

Assim, embora mudanças significativas venham acontecendo, o discurso das mulheres nessa pesquisa ainda indica uma hegemonia feminina quando se trata dos cuidados com os filhos. Diz uma participante:

Em relação à paternidade, essa é a minha maior queixa. Quando é preciso ficar com o filho à noite, ele não quer nem saber, apenas dorme. (Blog 1, 16/04/2017)

Sem o compartilhamento dos cuidados em casa, muitas mulheres buscam o apoio de especialistas que, nem sempre, são capazes de compreender o que elas demandam. A esse respeito Winnicott observa:

Se começarem a dar conselhos sobre essa intimidade, estarão pisando em solo perigoso, pois nem mãe, nem bebê precisam de conselhos. Em vez de conselhos, eles precisam de recursos ambientais que estimulem a confiança da mãe em si própria. Winnicott, 1987/1994, p.22)

Acreditamos que os compartilhamentos nos blogs possam funcionar como um, entre vários outros, recursos ambientais.

\section{CONCLUSÃO}

Talvez em nenhum outro momento da história assuntos tão privados, como a maternidade e as questões que a circundam, tenham se publicizado como atualmente. Para muitas mulheres, a escrita em blogs ou as trocas através de grupos virtuais são hoje parte integrante da construção da maternidade. Apesar do caráter público dos blogs, as mães parecem não temer expor sua individualidade, afetos e ambivalências. 
Verificamos que é exatamente no endereçamento ao outro que se localiza a intenção da escrita dos elementos maternos no ciberespaço. Este trabalho nos fez perceber que o olhar do outro, por via dos comentários, faz função de sustentação e suporte às experiências subjetivas no tocante à maternidade. Assim, a criação dos blogs de maternidade visa responder a uma demanda de compartilhamento de ideias, dúvidas, medos, desilusões, frustrações, alegrias, enfim, um rol de afetos que fazem parte da experiência de tornar-se mãe.

As redes sociais têm o poder incrível de unir pessoas que vivem fases parecidas. Se na época em que eu estava grávida de Lara eu tivesse conhecido tantas mães "solos", eu teria - sem dúvida, sido mais feliz. Me sentia sozinha demais e hoje já sei que não existe dor que não se possa compartilhar. (Blog 4, 12/02/17)

Ainda sobre a cumplicidade vivida entre mulheres que escrevem nos blogs, encontramos:

[...]. Pode ter certeza que não foi fácil falar sobre questões tão íntimas. Foram tempos de sofrimento abafando tudo isso tentando entender que na verdade não era eu quem estava errada, louca ou fora da curva. Teve mãe que imprimiu a matéria pra mostrar pro marido e pro terapeuta. Porque também se sentia assim. (Blog 5, 24/11/2015)

Nesse sentido, a escrita em blogs foi vista como um meio através do qual o sujeito pode elaborar suas experiências, bem como um espaço potencial no sentido winnicottiano, isto é, quando se torna capaz de potencializar a invenção do sujeito. Paradoxalmente, se ao espaço cibernético for direcionada uma busca errante por respostas estandardizadas, tal experiência poderá obstaculizar o alcance das saídas genuínas e fundamentais à maternidade, que deverão ser construídas de maneira singular.

Os papéis sociais e familiares são construídos a cada tempo a partir das contingências em voga. "Escutar" as mulheres, que de modo muito singular escrevem sobre suas experiências com a maternidade, nos permitiu evidenciar um ponto de virada. Apesar de herdeiras de um antigo modelo de idealização da "boa e devotada mãe", as mulheres de nosso tempo acenam para novos horizontes cujo exercício da maternidade vai sendo criado e recriado a partir das contingências de cada realidade familiar e social.

Importante salientar que ainda hoje é possível verificar uma dissonância discursiva entre a mulher livre, empreendedora, moderna, independente, e algumas expressões "maternalistas" que demandam disponibilidade e devoção integral aos filhos, de modo que para atendê-los, os anseios e desejos da mulher devam ser colocados em suspenso, ainda que provisoriamente. Evidentemente que afetos, como culpa e sentimento de impotência fazem parte da história individual e subjetiva de cada mulher, contudo, tais experiências muitas vezes são expandidas, fazendo parte do contingente de mulheres de uma dada sociedade. Nesse nível de expressão, é possível pensarmos em condições sócio- 
políticas que precisam ser transformadas, o que demanda ações coletivas e iniciativas governamentais.

De outra parte, a criação de fóruns e coletivos de mulheres que criam formas de apoio recíprocos tem sido bastante importante quando consideramos as transformações no exercício da maternidade. Trata-se de reinvenções, no sentido em que cada "ponto de virada" está circunscrito a um tempo e às demandas contingenciais, portanto, elas nunca serão esgotadas. No momento, a articulação e o debate que ocorrem nas redes sociais têm sido um auxiliar importante no apoio às mulheres que conseguem aí dar voz aos seus conflitos, o que favorece uma relação mais criativa com seus bebês e com seu meio.

Suspender as idealizações em torno da figura materna talvez seja a alternativa que melhor se coaduna com o retrato que está à nossa frente. Cada mulher, cada família, em cada contexto sociocultural sinalizará o que é possível no que tange aos cuidados com os filhos pequenos. Essa proposição corresponde à ética própria da psicanálise, a saber, a valorização da dimensão da singularidade e subjetividade nos diversos contextos da vida humana. Consideramos assim, que tais reflexões podem suscitar novos debates que permitam a invenção de formas criativas de ser mãe.

\section{DECLARAÇÃO DE CONFLITOS DE INTERESSE}

Não há conflito de interesse.

\section{REFERÊNCIAS}

Ariès, P. (1978). História social da criança e da família. Rio de Janeiro: LTC.

Belo, F. R. R., Guimarães, M. R., \& Fidelis, K. A. B. (2015). Pode um pai ser cuidadoso? Crítica à teoria da paternidade em Winnicott. Psicologia em Estudo, 20(2), 153-164. DOI: 10.4025/psicolestud. V 2012.24274

Benhaïm, M. (2007). Amor e ódio: a ambivalência do amor materno. Rio de Janeiro: Cia de Freud.

Braga, A. (2008). Personas materno-eletrônicas: feminilidade e interação no blog Mothern. Porto Alegre: Editora Sulina.

Ferreira, M.C., \& Aiello-Vaisberg. T.M.J. (2006). O pai 'suficientemente bom': algumas considerações sobre o cuidado na psicanálise winnicottiana. Mudanças - Psicologia da Saúde, 14(2), 136-142.

Iaconelli, V. (2015). Mal-estar na maternidade: do infanticídio à função materna. São Paulo: Annablume.

Lipovetsky, G. (2000). A terceira mulher: permanência e revolução do feminino.

(Trad. Maria Lucia Machado). São Paulo: Companhia das Letras.

Lisauskas, R. (2017a). Ser mãe é padecer na internet. Recuperado de http://emais.estadao.com.br/blogs/ser-mãe/ 
Lisauskas, R. (2017b). Mãe sem manual. Caxias do Sul: Belas Letras.

Lobo, L. (2007). Segredos Públicos: os blogs de mulheres no Brasil. Rio de Janeiro: Rocco.

Postman, N. (1999). O Desaparecimento da Infância. Rio de Janeiro: Graphia.

Winnicott, D.W. (2014). E o pai? In D. W. Winnicott, A criança e o seu mundo (pp. 127-133) (6a. Ed, Trad. À. Cabral). Rio de Janeiro: LTC. (original publicado em 1949).

Winnicott, D.W (2012). Os bebês e suas mães (p.16) (4a. Ed. Trad. Jefferson Luiz Camargo). São Paulo: Martins Fontes. (original publicado em 1988.)

Winnicott, D.W. (1989). A contribuição da mãe para a sociedade. In D. W. Winnicott, Tudo começa em casa (pp.97-100). (Trad. Paulo Sandler). São Paulo: Martins Fontes. (Original publicado em 1957).

Sobre as autoras

Maria Consuêlo Passos possui licenciatura em Psicologia pela Faculdade de Filosofia do Recife (1973), formação em Psicologia pela Faculdade de Filosofia do Recife (1973), mestrado em Psicologia pela Pontifícia Universidade Católica do Rio de Janeiro (1980) e doutorado em Psicologia (Psicologia Social) pela Pontifícia Universidade Católica de São Paulo (1991). Pesquisadora de família e desenvolvimento humano, tem experiência na área de Psicologia Social e Psicanálise, atuando principalmente nos seguintes temas: família, psicanálise da família, psicanálise e cultura, relação mãe-bebê, infância e adolescência. Professora do Departamento de Psicologia da Universidade Católica de Pernambuco, desde agosto de 2009, com atuação na Graduação e no PósGraduação em Psicologia Clínica. E-mail: mariaconsuelopassos@gmail.com Isabela Lemos Arteiro é doutora em Psicologia Clínica pela Universidade Católica de Pernambuco. Mestre em Psicologia Clínica pela Universidade Católica de Pernambuco (2007). Graduada em Psicologia pela Universidade do Oeste Paulista - UNOESTE (SP) - (2002). Especialista em Psicanálise pela Universidade Católica Dom Bosco - MS (2005). Professora Adjunta na Universidade Federal da Paraíba. E-mail: isabelalemos@gmail.com

A contribuição de cada autora pode ser atribuída como se segue: M. C. P. e I. L. A. contribuíram para a conceitualização, investigação e visualização do artigo; $M$. C. P. e I. L. A. fizeram a redação inicial do artigo (rascunho) e M. C. P. e I. L. A. são as responsáveis pela redação final (revisão e edição).

Recebido em: 03/06/2019

Revisado em: 16/08/2019

Aceito em: $19 / 12 / 2019$ 